\title{
Comments on the article "Clinical application of Nuss procedure for chest wall deformity in Poland syndrome"
}

\author{
Krystian Pawlak \\ Department of Thoracic Surgery, Poznan University of Medical Sciences, Poznan, Poland \\ Kardiochirurgia i Torakochirurgia Polska 2014; 11 (4): 424
}

\begin{abstract}
Poland's syndrome is a very rare type of chest deformation found in $1: 32,000-1: 52,500$ live births $[1,2]$. Its treatment most often involves the reconstruction of the mammary glands with the transposition of a pedicled muscle-skin flap using Marlex mesh [3, 4] or the repair of the chest's bone structure. The coexistence of multiple developmental defects of the chest constituting this syndrome and the asymmetric character of the deformation increase the difficulty of performing a successful correction. The authors of the present study describe a method of treating Poland's syndrome, employed in a 4-year-old female patient, using the minimally invasive Nuss method as the first stage of treatment, preparing the conditions for a final correction during puberty. However, performing the Nuss procedure on a 4-year-old asymptomatic child raises some questions. Although some authors believe that the Nuss procedure should be performed as early as possible, provided that the patient is at least 3 years old $[5,6]$, and that the method is safe and not burdened with a high rate of complications, achieving a satisfactory effect of correction in these Poland's syndrome patients is very challenging, as indicated by this report as well as others [7]. It appears that performing a single repair procedure that combines elements of the Ravitch method and the Nuss method during puberty, and, perhaps, supplementing it with mammary gland reconstruction, would improve not only internal, but
\end{abstract}

especially external correction. I also do not share the concern of the authors pertaining to the complications which can occur in classic plastic repair of the anterior thoracic wall. Complex correction of developmental thoracic defects should be selected as the treatment of choice in the case of large asymmetric deformations for which the Nuss method alone is insufficient. The complications occurring as a result of the two treatment methods are comparable.

\section{References}

1. Czeizel A, Vitez M, Lenz W. Birth prevalence of Poland sequence and proportion of its familial cases. Am J Med Genet 1990; 36: 524.

2. McGillivray BC, Lowry RB. Poland syndrome in British Columbia: incidence and reproductive experience of affected persons. Am J Med Genet 1977; 1: 65-74.

3. Fijałkowska M, Antoszewski B. Surgical treatment of patients with Poland's syndrome - own experience. Pol Przegl Chir 2011; 83: 662-667.

4. Urschel HC Jr. Poland syndrome. Semin Thorac Cardiovasc Surg 2009; 21: 89-94.

5. Park HJ, Sung SW, Park JK, Kim JJ, Jeon HW, Wang YP. How early can we repair pectus excavatum: the earlier the better? Eur J Cardiothorac Surg 2012; 42: 667-672.

6. Kim do JJ, Hwang JJ, Lee MK, Lee DY, Paik HC. Analysis of the Nuss procedure for pectus excavatum in different age groups. Ann Thorac Surg 2005; 80: 1073-1077.

7. Nishibayashi A, Tomita K, Yano K, Hosokawa K. Correction of complex chest wall deformity in Poland's syndrome using a modified Nuss procedure. J Plast Reconstr Aesthet Surg 2013; 66: e53-55. 